\title{
Androgen profiling in males of two high-fertility mouse models does not reveal a distinct phenotype but provides new reference values \\ for androgens in mice \\ FBN / Wilhelm-Stahl-Allee 2 / 18196 Dummerstorf / www.fbn-dummerstorf.de
}

Joachim M. Weitzel ${ }^{1}$, Marten Michaelis ${ }^{1}$, Alexander Sobczak ${ }^{1}$, Martina Langhammer ${ }^{2}$, Gerd Nürnberg ${ }^{2}$, Norbert Reinsch², Michaela F. Hartmann³ ${ }^{3}$, Stefan A. Wudy ${ }^{3}$, Jennifer Schön ${ }^{1}$

1 Institut für Fortpflanzungsbiologie and ${ }^{2}$ Institut für Genetik und Biometrie, Leibniz-Institut für Nutztierbiologie, FBN Dummerstorf; ${ }^{3}$ Steroid Research \& Mass Spectrometry Unit, Zentrum für Kinderheilkunde und Jugendmedizin, Justus Liebig Universität Giessen.

\section{Background:}

Animal models are valuable tools in fertility research. Worldwide, there are more than 1000 transgenic or knockout mouse models available showing a reproductive phenotype; almost all of them exhibit an infertile or at least subfertile phenotype. By contrast, animal models revealing an improved fertility phenotype are barely described. We developed two outbred mouse models exhibiting a 'high-fertility' phenotype. These mouse lines were generated via selection over a time period of more than 40 years and 170 generations. By now both mouse lines doubled the number of offspring as well as the total birth weight per litter.

The litter size in the two high-fertility mouse lines FL1 and FL2 almost doubled.

\begin{tabular}{|l|l|l|l|} 
& Ctrl (fem.) & FL1 (fem.) & FL2 (fem.) \\
\hline Ctrl (male) & 11.4 & 21.1 & 20.7 \\
\hline FL1 (male) & 11.9 & 22.0 & 21.7 \\
\hline FL2 (male) & 12.5 & 22.6 & 20.8 \\
\hline
\end{tabular}

The successful mating rates are between 82 and $96 \%$.

\begin{tabular}{|l|l|l|l|} 
& Ctrl (fem.) & FL1 (fem.) & FL2 (fem.) \\
\hline Ctrl (male) & $92 \%$ & $92 \%$ & $96 \%$ \\
\hline FL1 (male) & $94 \%$ & $90 \%$ & $94 \%$ \\
\hline FL2 (male) & $92 \%$ & $82 \%$ & $92 \%$
\end{tabular}

We performed a two-factorial experiment by mating males and females of the three different genotypes (fertility line \#1 (FL1), fertility line \#2 (FL2) and control line (ctrl)) in all 9 possible combinations. We observed that increased fertility performance almost completely depended on the genotype of the females. Though not significant, the largest effect has been observed for males of the FL2 line. We noticed that the two independent fertility lines warranted the phenotype 'high fertility' using different physiological strategies.

\section{Androgen values in the mice.}

In order to test whether this is reflected by different endocrine concentrations, we measured androgen concentrations in serum of males of the three lines (FL1, FL2, ctrl) using a gas chromatography-mass spectrometer (GC-MS) method. We measured testosterone concentrations between 5.0 and $6.4 \mathrm{ng} / \mathrm{ml}$ with no difference between the lines. We also measured other androgens (4 androstenedione: not detectable (nd) $-0.06 \mathrm{ng} / \mathrm{ml}$; dehydroepiandrosterone (DHEA): $\mathrm{nd}-0.31 \mathrm{ng} / \mathrm{ml}$; androstenediol: 0.14 to $0.39 \mathrm{ng} / \mathrm{ml}$; dihydrotestosterone (DHT): 0.08 to $0.19 \mathrm{ng} / \mathrm{ml}$ ).
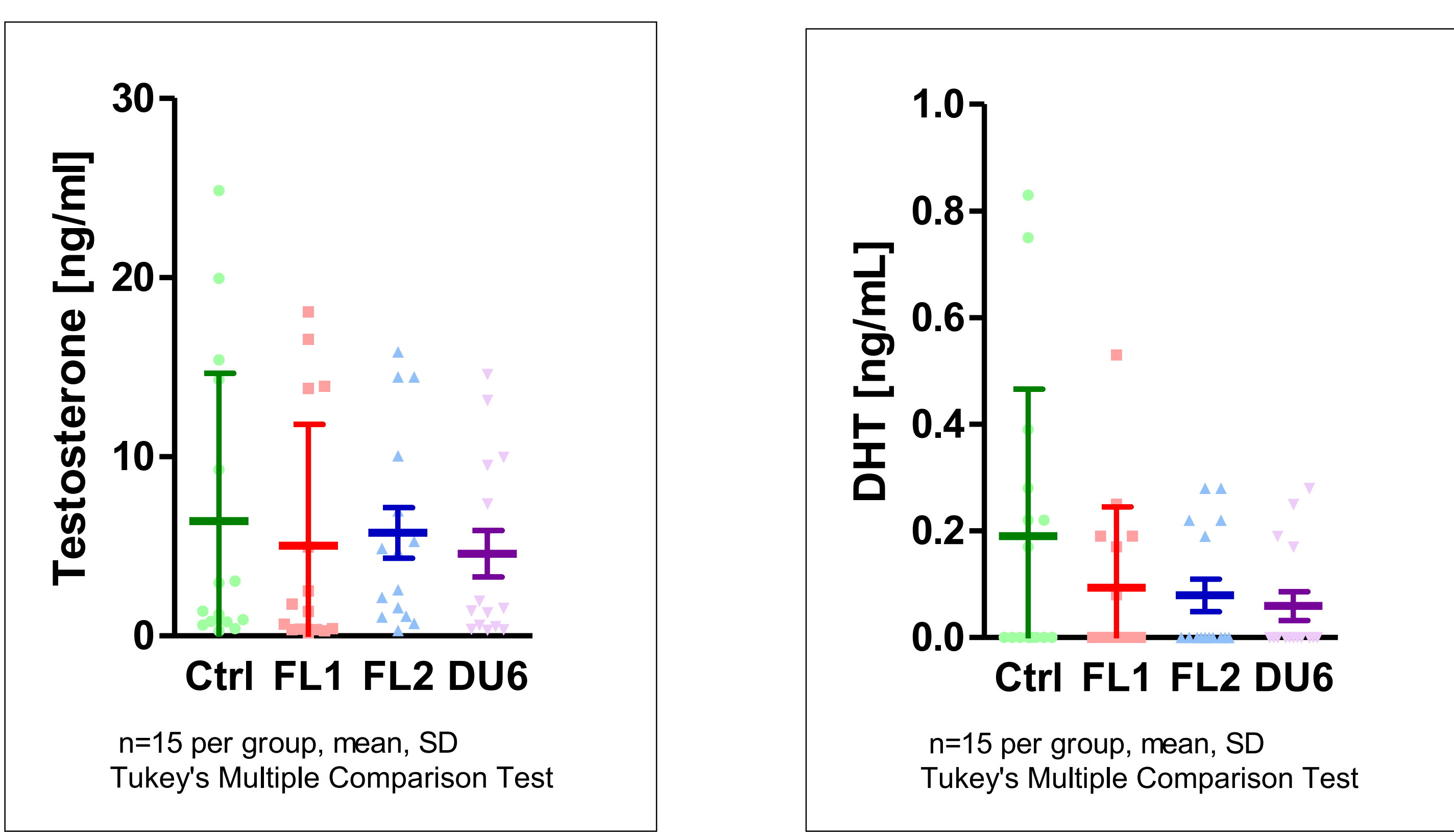
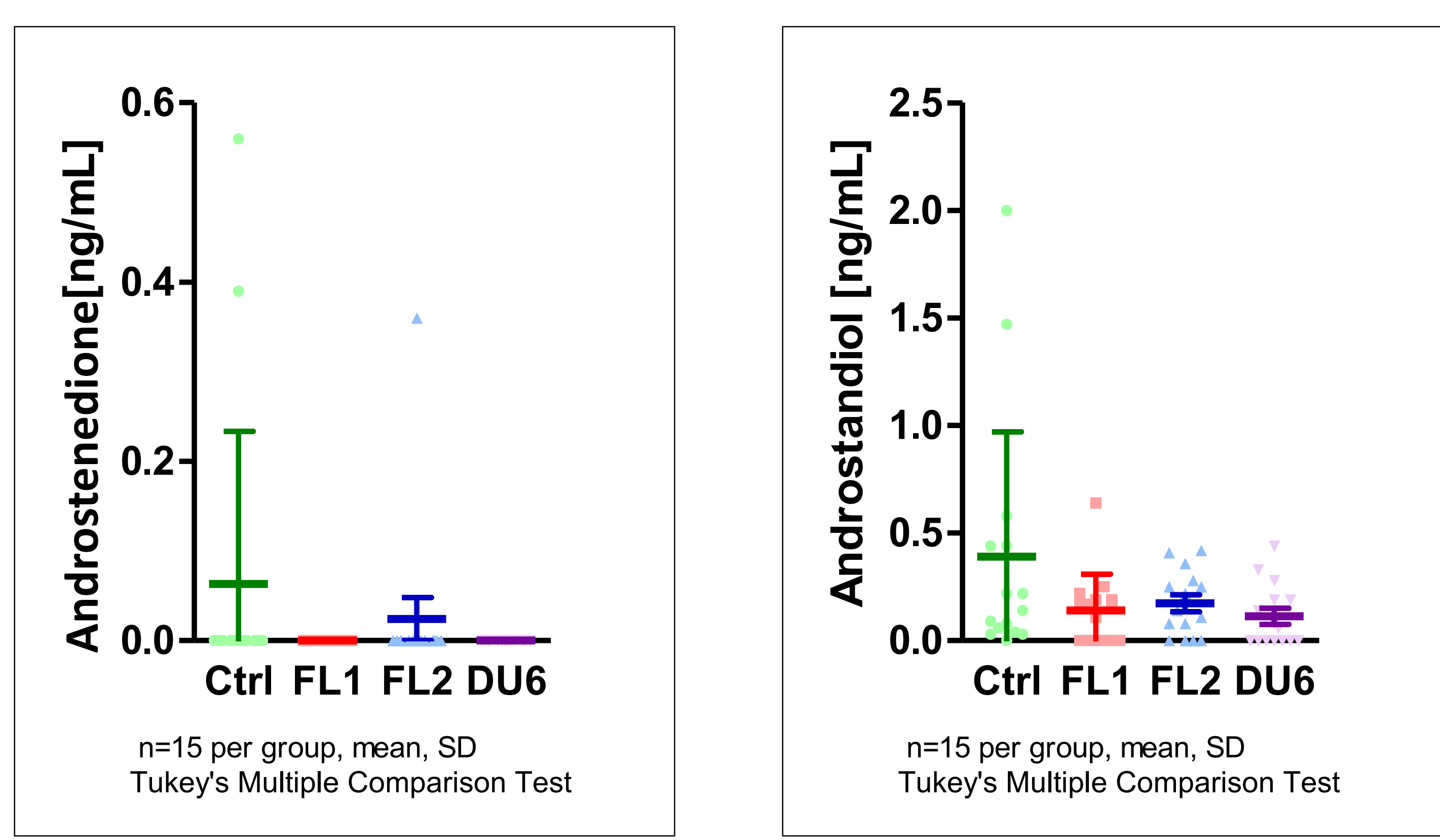

Androgen reference values in mice.

The androgen concentrations of DHT, DHEA, androstenedione and

androstenediol are at least 10-fold lower compared to testosterone. Since androgen concentrations in the mouse, measured by the "gold standard" GCMS, are barely described in the literature we have to consider these concentrations as reference values in mice.

\section{LEIBNIZ INSTITUTE} FOR FARM ANIMAL BIOLOGY 